\section{Parasitism data of Glossina palpalis and G. tachinoides (Diptera: Glossinidae) by trypanosome species in parts of Abia State, Nigeria}

\author{
Carmelita C. Ohaeri, Mark C. Eluwa \\ Department of Biological Sciences, \\ Michael Okpara University of Agriculture \\ Umudike, Umuahia Abia State, Nigeria
}

\section{Abstract}

Glossina species are important medical and agricultural vectors transmitting the African animal trypanosomes and also the agent of sleeping sickness in human. Parasitism data of Glossina species by trypanosomes were carried out over a period of one year, from April 2003 to March 2004 using bioconical traps to catch tsetse at some selected Local Government Areas of Abia State, Nigeria. Four hundred and twenty seven (427) flies were dissected and examined microscopically for the presence of trypanosome infection. The survey found Glossina palpalis as the predominant tsetse species in the area. Out of the 427 flies dissected, 17 (3.9\%) were infected with trypanosome. The highest infection was recorded among $G$. palpalis (3.7\%) and this was significantly higher $(\mathrm{P}<0.001)$ when compared with those of $G$. tachinoides (0.2\%). Female flies had higher infection than males $(2.3 \%$ as against $1.6 \%$, respectively). Majority of the infected flies were caught during rainy season (2.8\%) and few were caught in dry season (1.1\%). Twelve (2.8\%) of all the parasites were located in the proboscis indicating Trypanosoma vivax infection, while 5 (1.1\%) were from mid-gut of the flies indicating $T$. congolense infection. No parasite was observed in all the Glossina species caught at Ikwuano and Umuahia South areas, while trypanosome parasitism was highest in Glossina species caught at Isuikwuato, $2.5 \%$ of the flies in this area were parasitized. The low parasitic infection rate observed here indicates a marginal effect on the vector population of trypanosomes in Abia State, Nigeria.

\section{Introduction}

Tsetse flies (Glossina species) are important medical and agricultural vectors transmitting the African trypanosomes, the agent of sleeping sickness in human and also animal trypanosomiasis. Tsetse flies are blood-suck- ing dipterans in which both male and female feed exclusively on the blood of vertebrates for a few minutes every 2-3 days. ${ }^{1}$ The flies seek cover from high temperatures to conserve energy and plants provide shelter in all the biotypes. In some cases the flies take cover in plantations and under invasive bush in many areas of the tsetse fly belt of Africa and flies from such refugia are implicated in sleeping sickness epidemics. ${ }^{1}$ Trypanosomes replicate in tsetse fly and are transmitted through the tsetse saliva when the fly feeds on animal. Three main species groups of tsetse flies are responsible for transmission of trypanosomes. These are the morsitans, palpalis and fusca groups. Members of the morsitans group prefer the open woodland of the savannah; those of the palpalis group the shaded habitat immediately adjacent to rivers and lakes; while the fusca group occur in the high dense forest areas.

The management of trypanosomiasis relies heavily on the control of the vector, tsetse flies. ${ }^{2}$ Trypanosome biology is widely studied, while knowledge of tsetse flies is very limited, particularly in Abia State, which poses a serious hurdle to tsetse and trypanosome control. ${ }^{3}$ There are numerous studies on prevalence of trypanosome infections in tsetse flies in Nigeria and elsewhere. 4,5 The control of trypanosomiasis and the vector of its agent, tsetse fly still remains a major challenge in Nigeria and sub-Sahara Africa. Vast land meant for cultivation and animal production is abandoned due to tsetse infestation.6,7 This study was therefore undertaken to establish the rate of trypanosome infection in tsetse, and thereby assess the risk of trypanosome infection in Abia State, Nigeria.

\section{Materials and Methods}

\section{Study area}

Abia State in South-Eastern Nigeria constitutes the study area. The State lies approximately on latitude $4^{\circ} \mathrm{N}$ to $6^{\circ} \mathrm{N}$ and longitude $7^{\circ} \mathrm{E}$ to $8^{\circ} \mathrm{E}$, with mean annual rainfall of 187.7 $\mathrm{mm}$ (data were from Abia State Ministry of Lands and National Root Crop Research Institute Umudike, Nigeria).

The Local Government Areas (LGAs) of the State covered were Ikwuano, Umuahia South, Isuikwuato, Ohafia and Isiala Ngwa. These areas are located within the tropical rain forest or derived savannah vegetational zone. The choice of the study area was based on the earlier study. ${ }^{3}$

\section{Collection of tsetse flies}

Tsetse flies were caught using unbaited biconical traps ${ }^{8}$ bought from National Institute
Correspondence: Carmelita C. Ohaeri, Department of Biological Sciences, Michael Okpara University of Agriculture Umudike, PMB 7267 Umuahia Abia State, Nigeria.

Tel. +234.703.5213350.

E-mail: ohaeric2000@yahoo.co.uk

Key words: parasitism, Glossina, trypanosomes, season

Acknowledgements: this work is part of a Ph.D. thesis of C.C. Ohaeri submitted to Michael Okpara University of agriculture umudike, umuahia Abia State, Nigeria. The study was supported by the Federal government of Nigeria (Ref. FSBA/FGSS: PG/027GA). The authors would like to thank M. Uzoukwu of College of veterinary medicine for his valuable help.

Contributions: $\mathrm{CCO}$, main author and principal researcher; MCE, work supervision and proofreading.

Conflicts of interests: C.C. Ohaeri received support from Federal government of Nigeria under the Federal government postgraduate scholarship (Ref. FSBA/FGSS: PG/027GA) and have been duly acknowledged. The authors and their institution have no financial or personal relationship with anybody for this work.

Received for publication: 14 September 2011. Accepted for publication: 22 November 2011.

This work is licensed under a Creative Commons Attribution NonCommercial 3.0 License (CC BYNC 3.0).

(C) Copyright C.C. Ohaeri, M.C. Eluwa et al., 2010 Licensee PAGEPress, Italy

Veterinary Science Development 2011; 1:e17 doi:10.4081/vsd.2011.e17

for Trypanosomiasis Research Vom, Plateau State, Nigeria. Two traps were located where farm animals regularly graze at a distance of $20 \mathrm{~m}$ apart. The entrapped flies were harvested after $8 \mathrm{~h}$ of daylight every sampling day. Two visits were made to each LGA per month for consecutive 12 months (April 2003-March 2004). The flies caught were taken on the same day they were harvested to the Biological Science laboratory Michael Okpara University of Agriculture Umudike, for parasitological investigations.

\section{Dissection of tsetse flies \\ for trypanosomes}

Adult Glossina were identified, gender observed and species differentiated based on morphological characteristics. ${ }^{9-11}$ A total of 427 tsetse flies (comprised of randomly selected flies from each visit) were killed by gently pressing the thorax. Then, the wings and the 
legs were removed and the flies dissected within $24 \mathrm{~h}$ of capture under the dissecting microscope inside a drop of normal saline. Mouthpart dissections were performed on all the flies. In this the labrum and hypopharynx were carefully removed and centrally placed on clean microscope slide containing a drop of normal saline. The preparation was covered with a cover slip and then examined for trypanosomes under a light microscope at $\times 400$ magnification. The gut was also removed by slowly pulling the last abdominal intersegmentary membrane while holding firmly the terminal segment with a forceps. The gut was then ruptured in a drop of normal saline and the preparation examined for trypanosomes infection under a light microscope at $\times 400$ magnification. Salivary gland was also examined for infections. The salivary glands were removed by holding the thorax firmly with a forceps on clean microscope slide containing a drop of normal saline and the head gently pulled away with a dissecting pin. The salivary glands were cut and the preparation examined microscopically on a drop of normal saline. The species of trypanosome infecting the flies was established based on site of infection.12-13 Mouthpart (proboscis) infections with no detectable midgut infection were designated $T$. vivax type infection; midgut plus proboscis positive infections were designated T. congolense type and salivary gland positive infections were designated $T$. brucei type infection. The other biting flies were identified (Tabanid, Stomoxy), counted and subsequently discarded without further studies.

\section{Statistical analysis}

The data obtained from this study were subjected to analysis using student's $t$-test. A P value of 0.05 or less was considered significant.

\section{Results}

\section{Vector trypanosome infection rate}

The total number of tsetse flies caught for dissection from the five LGAs (Ikwuano, Isuikwuato, Ohafia, Umuahia South and Isiala-Ngwa) involved in the present study stood at 427 and their infection rates are presented in Table 1. The overall tsetse infection rate found in this study is $3.9 \%$. The highest infection rate was recorded among $G$. palpalis (3.7\%) and this was significantly higher $(\mathrm{P}<0.001)$ when compared with $G$. tachinoides (0.2\%).

The infection in overall female was statistically different $(\mathrm{P}<0.05)$ from those of male species and in every gender category, infection rate was still higher $(\mathrm{P}<0.01)$ with $G$. palpalis.
There was no significant difference $(\mathrm{P}>0.05)$ in type of trypanosome species infection found in male and female of the two Glossina species studied. There was significant difference $(\mathrm{P}<0.001)$ in the trypanosome infection rate of the flies collected from different localities (Table 2). There was no infection in the flies caught in Ikwuano and Umuahia South Local Government Areas, though the prevalence rates of tsetse in these areas were very low to make in-depth comparison with Isuikwuato and Ohafia LGAs.

\section{Seasonal tsetse infection rate by month}

The prevalence of infection varied between months (Figure 1). The prevalence of infection ranged from $0(0.0 \%$, minimum) in November through April to 7 (1.6\%, maximum) in July, which followed the month with the highest tsetse catch.

\section{Site of infection of Glossina species and trypanosomes incriminated}

Out of the 17 Glossina species infected, 12 (2.8\%) had mouthpart infections with no detectable midgut infection (Trypanosomes in the proboscis only) and these were designated T. vivax type of infections (Table 3 ). Eleven (2.6\%) were from $G$. palpalis, which accounted for $64.7 \%$ of overall infections. Five (1.1\%) of the positive flies had midgut plus proboscis infection and were designated T. congolense group and all were from $G$. palpalis. The prevalence of T. vivax infection was significantly higher $(\mathrm{P}<0.001)$ than that of $T$. congolense infection (Table 3). T. brucei (salivary gland positive) was not found in the study.

Table 1. Trypanosome infection rates in Glossina species.

\begin{tabular}{lccccc} 
Glossina species & Sex & No. dissected & No. infected & $\%$ infected & $\begin{array}{c}\text { Species } \\
\text { total (\%) }\end{array}$ \\
G. palpalis & Male & 180 & 7 & $1.6^{* *}$ & \\
& Female & 192 & 9 & $2.1^{* *}$ & $16(3.7)^{* * *}$ \\
\multirow{2}{*}{ G. tachinoides } & Male & 25 & 0 & 0 & $1(0.2)$ \\
& Female & 30 & 1 & 0.2 & \\
\hline Total & Male & 205 & 7 & $1.6^{*}$ & $17(3.9)$ \\
\multirow{2}{*}{ Overall Total } & Female & 222 & 10 & 2.3 & \\
\hline
\end{tabular}

${ }^{* *} \mathrm{P}<0.01$ vs genders in G. tachinoides; ${ }^{* *} * \mathrm{P}<0.001$ us G. tachinoides; ${ }^{*} \mathrm{P}<0.05$ vs total female.

Table 2. Effects of sampling locations on infection rate.

\begin{tabular}{lccc} 
Sampling location & No. dissected & No. infected & \% infected \\
Ikwuano & 2 & 0 & 0 \\
Isuikwuato & 191 & 11 & $2.5^{*}$ \\
\hline Ohafia & 180 & 5 & 1.2 \\
Isiala Ngwa & 31 & 1 & 0.2 \\
\hline Umuahia South & 23 & 0 & 0 \\
Total & 427 & 17 & 3.9 \\
\hline
\end{tabular}

As compared to other locations $* \mathrm{P}<0.001$.

Table 3. Site of infection and trypanosome species incriminated in Glossina species $(n=427)$.

\begin{tabular}{|c|c|c|c|c|c|c|}
\hline \multicolumn{2}{|c|}{ Glossina species } & \multirow[t]{2}{*}{ No. infected } & \multicolumn{3}{|c|}{ Site of infection } & \multirow{2}{*}{$\begin{array}{l}\text { Trypanosome } \\
\text { species }\end{array}$} \\
\hline & & & Prob & MG & Sal & \\
\hline \multirow[t]{2}{*}{ G.palpalis } & Male & 7 & 5 & 2 & 0 & $\operatorname{Tv}(5), \operatorname{Tc}(2)$ \\
\hline & Female & 9 & 6 & 3 & 0 & $\operatorname{Tv}(6), \operatorname{Tc}(3)$ \\
\hline \multirow[t]{2}{*}{ G. tachinoides } & Male & 0 & 0 & 0 & 0 & \\
\hline & Female & 1 & 1 & 0 & 0 & $\operatorname{Tv}(1)$ \\
\hline \multirow[t]{4}{*}{ Total } & Male & 7 & $5^{\mathrm{a}}$ & $2^{\mathrm{a}}$ & 0 & \\
\hline & Female & 10 & 7 & 3 & 0 & \\
\hline & Total & 17 & $12^{\mathrm{b}}$ & 5 & 0 & $\operatorname{Tv}(12) c$, Tc (5) \\
\hline & $\%$ & 3.9 & 2.8 & 1.1 & 0.0 & \\
\hline
\end{tabular}

Prob, Proboscis; MG, mid-gut; Sal, salivary gland; Tv, Trypanosoma vivax; Tc, T. congolense; $\mathrm{P}>0.05$ vs total female species; $\mathrm{bP}<0.001$ vs other sites of infection; $\mathrm{c} P<0.001$ us T. congolense. 


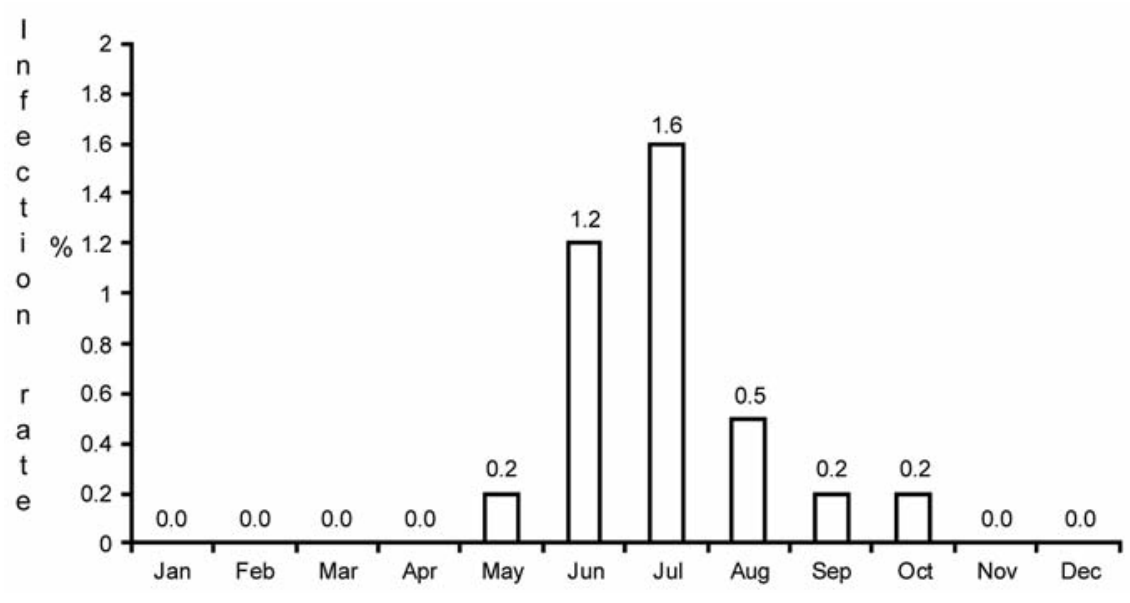

Figure 1. Seasonal variation in infection rates of Glossina species by month.

\section{Discussion}

The control of tsetse flies and trypanosomiasis requires constant assessment of the risk of trypanosome transmission. Study of parasitism of the vector will go a long way to improve animal production especially in an area with food insufficiency like Abia State, Nigeria. Most importantly the State forms a favourable settlement for cattle nomads due to its suitable humidity and vegetation and this livestock movement can influence the rate of trypanosome infection.

The highest infection rate recorded among G. palpalis could mean that it has better vectoral capacity than $G$. tachinoides, besides $G$. palpalis was found to be more prevalent in the study area. ${ }^{3}$ The infection in overall female was statistically higher than those of male species probably due to the longevity of females, which carry parasites and in every gender category, infection rate was still higher with $G$. palpalis, which further supports the vectoral superiority of $G$. palpalis. The size of tsetse flies is also often associated with vectoral capacity parameters. ${ }^{14}$ Infection rate is influenced by the presence of the host and this could account for variation or low/absence of infection observed in many localities in this study. Probably, areas with higher infection might have been influenced by settlement of semi-nomadic herds, which in most cases may be infected and go unno- ticed and untreated thus rendering the break in transmission cycle difficult 15 and at the same time introducing the infection where it does not exist as the animals pass through. Moreover the risk of transmission primarily depends on the intensity of contact between hosts and vectors.

Seasonal variation in the prevalence of trypanosome infection of tsetse has been previously reported ${ }^{9}$ and this is in agreement with the result of this study. The effect of rainfall might have been highly apparent and as such low pastoral movement are encouraged during this season. G. palpalis harboured most of the infections detected, which means that it supports the development of both T. vivax and T. congolense than $G$. tachinoides. These findings evidently revealed that tsetse flies in Abia State had low infection rate and as such the risk of trypanosomiasis transmission is very minimal.

\section{References}

1. Syed Z, Guerin PM. Tsetse flies are attracted to the plant Lantana camara. J Insect Physiol 2004;50:43-50.

2. Aksoy S. Control of tsetse flies and trypanosomes using molecular genetics. Vet Parasitol 2003;115:125-45.

3. Ohaeri CC, Eluwa MC. The population Structure and Physiological Status of
Tsetse flies in Abia State, Nigeria. J Anim Vet Adv 2007; 6:513-6.

4. Kalu A0, Uzoigwe NR. Tsetse and Trypanosomiasis on the Jos Plateau: observations on outbreaks in Barkin-Ladi Local Government Area. Trop Vet 1996;14: 117-26.

5. Woolhouse MEJ, McNamara JJ, Hargreve JW, Bealby KA. Distribution and abundance of trypanosome (subgenus Nannomonas). Infection of the tsetse fly Glossina pallidipes in Southern Africa. Mol Ecol 1996; 5:11-8.

6. Egwu G0, Onyelili PA, Brisibe F, et al. The combined use of Difluoromethyllornithine (DFM0) and Isomethamidium in the treatment of experimental late stage Trypanosoma brucei infection in rats. Trop Vet 1993;11:57-67.

7. Chadenga V. Epideemiology and control of trypanosomiasis. Onderstepoort J Vet Res 1994; 61:385-90.

8. Challier A, Laveissiere C. Un nouveau piege pour la capture des glossines, (Glossina: Diptera- Muscidae) decription et essays sur le terrain. Cah ORSTOM ser Ent Med Parasit 1973;11:251-62.

9. Davies H. Tsetse flies in Nigeria, 3rd ed. Oxford University Press, Ibadan, 1977.

10. Smith KGV. Insects and other arthropods of medical importance. British Museum (Natural History) ed., London, 1973.

11. Service MW. A guide to Medical Entomology. Macmillan Int. College Ed., London, 1980.

12. Jordan AM. Trypanosome infection rate in the Glossina morsitans submorsitans Newst in Northern Nigeria. Bull Ent Res 1964;55:219-31.

13. FA0. Training manual for tsetse control personnel. Vol. 1. FAO ed., Rome, 1975.

14. De la Rocque S, Geoffrey B, Michel JF, et al. Tsetse flies wings, an identity card of the insect? Parasitol 2002;9:275-81.

15. Uzoukwu M. The problems of animal trypanosomiasis in the forest vegetation zone of Nigeria. pp 138-144 in Proc. 1st Nat. Conf. Tsetse and Trypanosomiasis Research and Control in Nigeria, 10-12 August 1981, Kaduna, Nigeria. 